\title{
Formation of the habitat as a complex eco- social-natural space of an ecologically oriented person
}

\author{
Tatiana Tyurina ${ }^{1, *}$ and Olga Ignatova ${ }^{1}$ \\ ${ }^{1}$ Don State Technical University, 1, Gagarin Sq., 344003, Rostov-on-Don, Russia
}

\begin{abstract}
The article deals with the problem of the formation of the environment as a complex eco-socio-natural space of an environmentally oriented person. The purpose of the article is to reveal the two-way influence of nature and man on the state of the environment and the ability of the individual to adapt to all kinds of natural metamorphoses based on their needs. The authors argue that the formation and development of an environmentally oriented personality is a key aspect in the formation of an eco-social and natural space. Balance environmental, moral and spiritual and social and economic needs of modern society, the harmonious coexistence with nature, the integration of rational nature management and stabilization of ecological conditions become prerogatives in the design of the surrounding environment of a modern human-centred sustainable development ecosociology. The article suggests criteria to evaluate the influence on the formation of an eco-social-natural space ecologically oriented individual operating your eco-thinking, aspiration to the organic nature of natural processes and the implementation of major social functions. In turn, the formed eco-social and natural space becomes a generator of cultural processes of an environmentally oriented personality.
\end{abstract}

\section{Introduction}

Throughout the entire course of human development, nature was presented as a complex mechanism for regulating the entire process of life activity in the context of the «mannature-society» system. However, in this system, human activity has not always been of a nature-saving nature. In the vast majority of cases, as a result of his economic activity, a person manifested himself as an active subject, which, according to K. Marx, creates, traces and even modifies the migration of substances between themselves and nature. Such a complex interaction of a person with the environment has a real impact on the formation of a person's eco-orientation in principle.

In our opinion, as in the opinion of many domestic and foreign scientists, the prospect of the existence and development of humanity can be ensured only in the conditions of joint development of the biosphere and society (co-evolution of humanity and the environment). In these conditions, the universal imperative today is a complete restructuring of the entire

*Corresponding author: dok217@ya.ru 
structure of socio-natural relations, norms and rules in order to ensure the harmonization of the relationship between society and nature through spiritual and educational activities, improving the ecological culture of society.

\section{Methodology}

Numerous studies of domestic and foreign scientists [3,4], as well as authors studies, have proved that the adverse impact of critical factors in the natural environment is manifested primarily through insufficient knowledge and understanding of the phenomena occurring, as well as the irrational use of natural resources and the lack of available scientific and technical achievements aimed at ensuring the creation and promotion of rational nature management. As a result, when it comes to the impact of natural factors on human society, it is important to separate the processes that affect our society, being exclusively anthropogenic, and those means that are used by people within the framework of the «mannature-society» system, while remaining entirely elements of nature.

Recently, factors that cause contradictions that are of a non-natural nature have played a significant role, and their role is very significant in the development of modern society. Under certain conditions of development, they can lead to stagnation of evolutionary development or even to the destruction of society as a separate system. It is worth noting that the mutual activity of man and nature has always depended on the state of the natural environment, and on the evolutionary development of mankind [18]. It should also be noted that this interaction was unstable, and all the existing processes in the natural environment had a complex and meaningful impact on all human life, changing the views of society as a whole on the phenomena occurring in nature. Under these conditions, the environment underwent changes not only for natural reasons, but also as a result of active human economic activity, which sometimes leads to a dramatic impoverishment of the riches of the surrounding natural environment. In particular, the ill-conceived use of chemical reagents and the disposal of household and industrial waste led to the degradation of soil, animal and plant diversity, changes in the chemical composition of the hydrosphere and lithosphere, the transformation of the atmosphere, and ultimately to climate change in the corresponding natural areas. Thus, it becomes obvious that the relationship between man and the environment is given priority.

In a situation of global ecological crisis resulting from the negative effects of scientific and technological progress and industrialization, humanity was faced with a new acute environmental problems such as climate change on a planetary scale, pollution of the atmosphere, ocean, soil and Land cover damage to the ozone layer and the increase of UV radiation, the greenhouse effect, the loss of biological diversity of the planet; the most serious environmental problem is pollution of the environment municipal waste.

It should be noted that the unreasonable use of natural resources leads to a negative impact on the nature of the person and society as a whole, becoming a prerequisite and source of new infections and diseases, the transformation of human genetic diversity as a special biological species and other negative processes and phenomenes.

The entire history of the evolutionary development of the natural environment proves the fact that nature, having a direct impact on the state of the environment as a whole, encouraged all living organisms, including humans, to adapt to all kinds of metamorphoses of natural conditions in certain territories. However, in modern conditions, a person himself shows considerable activity in the use of natural resources and changing the natural environment, based on his needs. It should be noted that this economic activity often does not sufficiently contribute to the restoration of the natural balance necessary to improve the standard of living of the population. In this regard, the interdisciplinarity of knowledge about the influence of the social factor on the formation of the eco-socio-natural space, as 
well as the formation and development of environmentally oriented thinking, can allow us to fully assess the entire volume of the socio-natural load that has a negative effect on all natural and economic activities of modern society [5].

Thus, the increase in the volume and quality of scientific research in the development of the process of greening the natural, socio-economic and other systems in conditions of high intensity nature use and environmental action gets undoubted relevance for conservation of nature, and to protect the health of human society. Also, a significant increase in the number of scientific works in the field of ecology and nature management in recent years indicates certain positive changes in the development of the labor force in all areas of environmental management. On the other hand, it reveals a still high level of failures in terms of nature management and environmental protection, which bring enormous damage to the country's economy, natural resources and their restoration.

The greening of the entire social world order is the main idea of our previous research [16]. At the same time, we give an important role to the value foundations of human existence and the greening of the human environment - a concept that characterizes the development of the environment as a complex system with harmoniously functioning social, economic, environmental and other principles of modern development.

In our works, we assume that the greening of a person and his environment can be carried out through the formation and development of value orientations of each person. The greening of human society and its environment is achieved through the implementation of targeted, meaningful, activity-based and evaluative-effective components. For example, the target component implies an environmentally oriented awareness and understanding of each level of socialization of a person and his or her universal values - personal, family, national-through existing social institutions - family, school, state. It also means understanding social behavior that will be in harmony with the natural environment.

The content component is characterized by two components - knowledge and cultural. The knowledge component is based on the still existing passivity of the eco-consciousness of modern man and a weak understanding of responsibility for the environment surrounding him. However, it is worth noting that over time, this passivity becomes more and more noticeable in the active phase due to the worsening ecological imbalance between society and the world around it. We associate the cultural component with the awareness of cultural tradition as a component of human ecological activity. Traditions and customs in a relatively unchanged form are preserved, accumulated and passed on from generation to generation for a long time, thereby enriching the spiritual world of society as a whole. They maintain the unity of the socio-historical experience of the people, connecting their past, present and future into an inseparable whole.

The activity component appeals to the formation of ecological self-consciousness of a modern person due to the use of certain active methods and technologies, namely, integration, individualization, education of social and ecosystem ties. The current norms and basic principles of environmental ethics - respect for nature, environmental responsibility and justice, conservation of biodiversity, caution-are a set of resources that ensure the process of interaction between man and nature, contribute to the preservation of security and the stability of the socio-natural system. The result is a change in the perception of environmentally oriented norms and values in the process of co-natural socialization of human society. The evaluation and performance component is a reflection on the above-mentioned aspects with an element of analytics and synthetic foresight for the optimal scenario for the future of human civilization. As a result, there is a value paradigm of modernity, which forms value ideas about an environmentally oriented person, helps him to find a worthy niche in society and nature.

At the same time, we should not forget that the formation of living space is a two - way process. This is because the space creates the person in the course of their life exactly the 
same as the environment influences the person, to its environment, resulting in a certain level of consciousness, behavior as a moral person [7], and the lifestyle of a person and society as a whole.

The characteristic features of a complex eco-social-natural space are determined by the peculiarities of the functioning and development of a person as a biosocial being. The formation of the eco-social and natural space involves the development of the existing subspace of modern society, which, in turn, is represented by a complex of components. On the one hand, the external component implies a specific society of the individual, including technological, cultural, and moral features. On the other hand, the internal component assumes the presence of personal cultural and psychological characteristics of the individual and its special spiritual and moral worldview

The specific manifestation of human activity is caused by the influence of a combination of factors, both external and internal components. In turn, the diverse human activity causes radical changes in the entire ecological space, which is the reason for its deep transformation. The changed space formed in this way indirectly influences the personality and causes its transformation, which changes the physiological state, worldview and nature of activity.

A distinctive feature of the eco-social-natural space is the formation and functioning on the basis of human economic activity, which is the main system-forming factor. It should be emphasized that the cultural, ethical and spiritual aspects represent the necessary ecological conditions, representing a special mechanism for the adaptation of humanity as a biological species to survive in a complex eco-social and natural space.

Balance environmental, moral, spiritual and socio-economic needs of the modern society as a result of the humanization of modern education [15], the harmony of coexistence with nature, the integration of rationalization of nature management and stabilization of the ecological situation since the end of the 20th century have become prerogatives in the design of the living environment of a modern person, oriented on sustainable eco-social-natural development. At the same time, the holistic consideration of all categories of environmental aspects (abiotic, biotic, anthropogenic, etc.) in urban planning becomes a guarantee that the formed habitat can give a person the necessary socio-ecological comfort.

Currently, according to many researchers [8], more than half of the world's population lives in cities, which makes the formation of a healthy urban environment one of the main priorities. At the same time, urbanization inevitably leads to radical changes in the socioecological state of the environment, especially expressed in large cities and urban agglomerations, including the negative consequences of scientific and technological progress and the development of industrial production.

It should be noted that the global nature of the adverse anthropogenic impact on the human environment was first recorded and became the subject of extensive discussion at the United Nations Conference on the Environment (Stockholm, 1972). Over the past decades, global problems caused by human activities have only increased, making the need for scientific research in this area and practical measures more urgent. Overcoming the negative impact of urbanization becomes an objective need of the human community.

Cities are known to have both benefits and risks to public health. It is scientifically proven that mood and anxiety disorders are more common in urban residents, and the incidence of mental illness increases significantly in people born and raised in cities $[2,6]$. So, in his work, Murzin A.D. [14] operates on the ideas of R. Park [10] and Belyakova E.A. [13] about the classification of components of the modern urban environment (Fig. 1). 


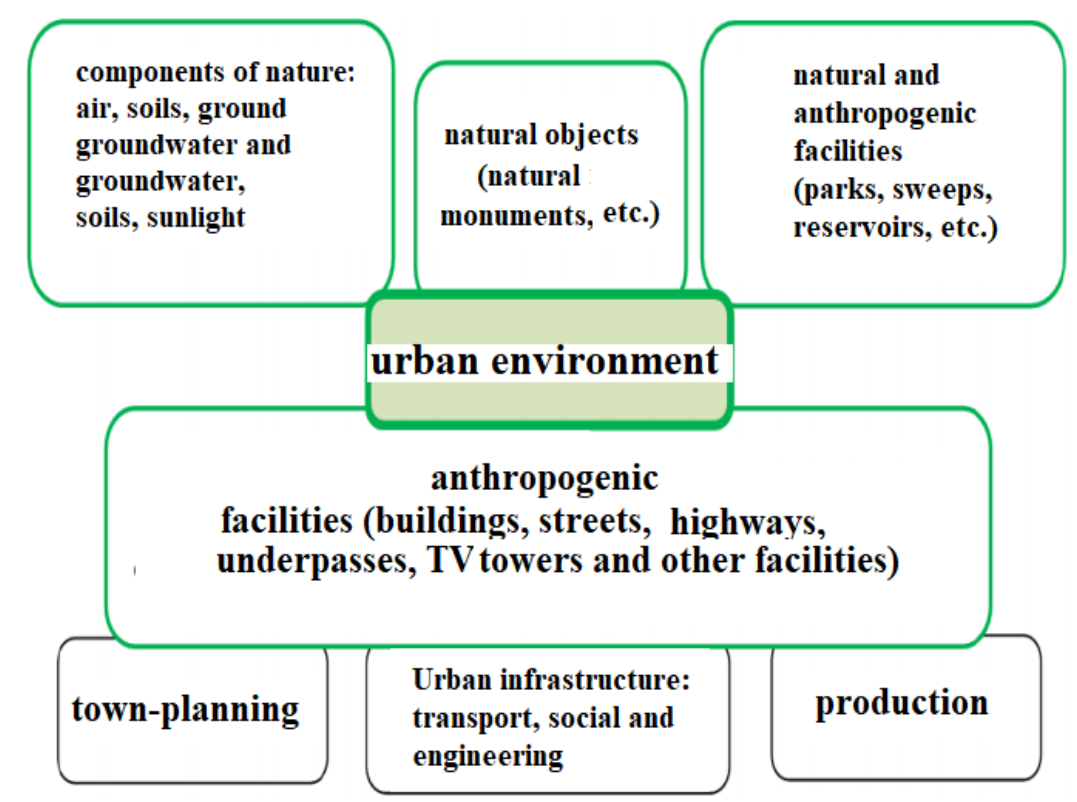

Fig. 1. Urban habitat, main components according to Belyakova E.A.

\section{Results}

In our opinion, in the context of the formation of the socio-natural space of an environmentally oriented person, this classification can be interpreted in the following way: each element of the environment has its own semantic load and should be carefully evaluated in terms of its role in improving the overall environmental situation, improving the quality of life of a modern environmentally oriented person.

Thus, the result of the interaction of the individual's nature with the environment is presented as a multi-level formation, including two levels: social (cultural) and biotic, which are the basis of social development. These levels imply ecological, economic, political, and cultural aspects that are realized through spatial, economic, political, and moral connections.

From this point of view, any component of the formed environmentally oriented social space should work to create a greater balance, harmony, and sustainability. Sustainability, in our understanding, is the key to environmentally-oriented planning [17]. The implementation of the ecobalance in a sustainable system of living ecospace is achieved by the fact that each element performs many different functions. Thus, the necessary conditions can be created for a comfortable and stable life, increasing the viability of all the constituent elements of the environment.

The sustainability of an environmentally oriented space appeals to such fundamental human needs as clean air, healthy food, privacy, direct contact with flora and fauna, social security, etc. As a result, the creation of favorable conditions for the formation of a general ecological situation plays an extremely important role in finding solutions to the problems of forming an eco-social-natural space that can also ensure the protection of public health [12].

Summarizing the above, we propose the following principles for the formation of the environment as a complex eco-socio-natural space of an environmentally oriented person (Table 1): 
Table 1. Fundamental criteria for the formation of an eco-social natural space of an ecologically oriented personality.

\begin{tabular}{|c|c|c|c|c|c|}
\hline & $\begin{array}{c}\text { Natural eco } \\
\text { processes }\end{array}$ & $\begin{array}{l}\text { Biological } \\
\text { positivism }\end{array}$ & $\begin{array}{l}\text { Efficiency of } \\
\text { interaction } \\
\text { between the } \\
\text { components of } \\
\text { the human } \\
\text { environment }\end{array}$ & $\begin{array}{c}\text { Autonomous } \\
\text { life support } \\
\text { systems }\end{array}$ & $\begin{array}{l}\text { Reference point } \\
\text { for the use of } \\
\text { materials of the } \\
\text { category of } \\
\text { environmentally } \\
\text { friendly }\end{array}$ \\
\hline 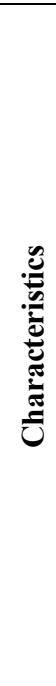 & $\begin{array}{c}\text { restoration of } \\
\text { flora and fauna, } \\
\text { increase of its } \\
\text { biodiversity, } \\
\text { increase of the } \\
\text { soil layer in the } \\
\text { territories of } \\
\text { significant } \\
\text { house-side } \\
\text { landscape } \\
\text { improvement }\end{array}$ & $\begin{array}{c}\text { application of } \\
\text { flora and fauna } \\
\text { as an } \\
\text { architectural } \\
\text { element of the } \\
\text { territory of } \\
\text { human } \\
\text { habitation }\end{array}$ & $\begin{array}{c}\text { natural and man- } \\
\text { made objects } \\
\text { (parks, squares, } \\
\text { landscape } \\
\text { formations...), } \\
\text { engineering } \\
\text { infrastructure } \\
\text { objects (roads, } \\
\text { bridges...) the so- } \\
\text { called «urban } \\
\text { fabric» (houses, } \\
\text { school buildings, } \\
\text { kindergartens...) }\end{array}$ & $\begin{array}{l}\text { local heat and } \\
\text { electricity } \\
\text { supply with } \\
\text { the use of } \\
\text { renewable } \\
\text { energy } \\
\text { sources; solar } \\
\text { power plants; } \\
\text { systems for } \\
\text { collecting, } \\
\text { using and } \\
\text { recycling } \\
\text { rainwater for } \\
\text { technical } \\
\text { needs; local } \\
\text { wastewater } \\
\text { treatment, } \\
\text { waste } \\
\text { recycling }\end{array}$ & $\begin{array}{l}\text { application in the } \\
\text { construction of } \\
\text { wood, stone, } \\
\text { ceramics, etc. } \\
\text { (low cost } \\
\text { accessibility and } \\
\text { safety for humans, } \\
\text { easy to recycle, } \\
\text { recyclable and } \\
\text { recyclable }\end{array}$ \\
\hline
\end{tabular}

Based on the above-mentioned criteria, when forming an eco-social-natural space, an environmentally oriented person operates with his eco-thinking, strives for the organic nature of natural processes and the implementation of the most important social functions. At the same time, the eco-social-natural space becomes a generator of cultural processes of an environmentally oriented personality.

\section{Conclusion}

In conclusion I want to note that the processes taking place today in the environment, in the intensification of science and technology commendable, as that can be traced ecosociology and scientific-technical nature of the system «man-nature-society», while eco-social space is based and operates on the basis of human activity.

At the same time, attention should be paid to the fact that some scientific approaches to solving urgent environmental problems in the field of socio-economic policy do not fully ensure the preservation of the natural potential of the territories.

In this regard, there is a need for new scientific and technical environmentally oriented research within the framework of the formation and development of rational nature management, the formation of the environment as a complex eco-social-natural space of an environmentally oriented person.

\section{References}

1. M. Adli, M. Berger, E.-L. Brakemeier et al., The Lancet Psychiatry 4(3), 183-185 (2017) DOI: 10.1016 / s2215-0366 (16) 30371-6 
2. C. Akdeniz, H. Tost, A. Meyer-Lindenberg, Social Psychiatry and Psychiatric Epidemiology 49(4), 507-517 (2014) DOI: 10.1007 / s00127-014-0858-4

3. J.A. Belaire, L.M. Westphal, E.S. Minor, Landscape Ecology 31, 401-413 (2016) https://DOI.org/10.1007/s10980-015-0256-7.

4. C. Chen, S. Nakagawa, Challenges 9(2) (2018) DOI: 10.3390 / challe9020041

5. M. Gandy, Area 47(2), 150-154 (2015) DOI: $10.1111 /$ area.12162

6. J. van Os, G. Kenis, B.P.F. Rutten, Nature 468, 203-212 (2010) DOI: 10.1038 / nature09563

7. Ji ří Mareš, Kontakt 18(3), e137-e144 (2016) DOI: 10.1016 / j.kontakt.2016.07.001

8. F. Lederbogen, P. Kirsch, L. Haddad et al., Nature 474(7352), 498-501 (2011) DOI: 10.1038 / nature 10190

9. J. Mills, P. Weinstein, N. Gellie et al., Restoration Ecology 25(6), 866-872 (2017) DOI: $10.1111 /$ rec. 12610

10. R.E. Park, The City. Suggestions for Investigation of Human Behavior in the Urban Environment. Selected essays (INION RAN, Moscow, 2011)

11. P.A. Sandifer, A.E. Sutton-Grier, B.P. Ward, Ecosystem Services 12, 1-15 (2015) DOI: 10.1016 / j.ecoser.2014.12.007

12. M. Soga, K.J. Gaston, Proceedings of the Royal Society B: Biological Sciences 287(1918), 20191882 (2020) DOI: 10.1098 / rspb.2019.1882

13. E.A. Belyakova, N.Yu. Ulitskaya, D.A. Ukhanov, Education and Science in the Modern World. Innovation 1, 167 (2020)

14. A.D. Murzin, Economy and Ecology of Territorial Entities 4(3), 53-59 (2020) https://DOI.org/10.23947/2413-1474-2020-4-3-53-59

15. E.A. Pushkareva, Yu.V. Pushkarev, Siberian International 17, 188-191 (2015)

16. T.A. Tyurina, Value guidelines in the system of socioprival interaction, collection: XIX All-Russia. stud.scientific-practical conf. (Nizhnevartovsk State University, 2017)

17. T.A. Tyurina, Bulletin of the Buryat State University 4-3, 10-18 (2018)

18. A.S. Cheshev, N.V. Alieva, Economics and ecology of territorial entities 1, 6-10 (2017) 